\title{
Interpersonal Relationship and Its Effect on Treatment Compliance in Patients with Type-2 Diabetes Mellitus
}

\author{
Fransiskus Samuel Renaldi ${ }^{1}$, Woro Riyadina ${ }^{2}$, Muhammad Qamar ${ }^{3}$, Rani Sauriasari ${ }^{*}$ \\ ${ }^{1}$ Faculty of Pharmacy, Universitas Indonesia, Depok, West Java, Indonesia \\ ${ }^{2}$ National Institute of Health Research and Development, Ministry of Health Republic of Indonesia, Jakarta, Indonesia \\ ${ }^{3}$ Department of Clinical Pharmacy, Faculty of Pharmacy, MAHSA University, Bandar Saujana Putra, 42610 Jenjarom, Kuala \\ Langat, Selangor, Malaysia
}

\begin{abstract}
Type-2 diabetes mellitus has become a chronic disease that can lead to serious complications and can only be prevented by compliant treatment of the patients. Compliance can be influenced by various factors, one of which is interpersonal factors. This study aimed to identify various interpersonal relationship problems between patients and healthcare workers that can affect their treatment compliance behavior. This study employed a qualitative design with phenomenological methods. This research was conducted in Central Bogor City in March-August 2020. The data were collected by conducting in-depth interviews with 20 type- 2 diabetes mellitus patients who had been confirmed by the Community Health Center and focus group discussions with 12 healthcare workers consisting of doctors, pharmacists, nutritionists, and nurses. The data were then transcribed and content clouds analysis was carried out. The results showed that most of the patients $(76 \%)$ followed the advice given by healthcare workers to carry out routine controls. This is a form of patients' trust in healthcare workers as their health consultants. The trust arises from the convenience of interaction between the two parties. Providing adequate information will increase patients' understanding and encourage them to take appropriate action for themselves. As many as 12 out of 20 patients chose the Community Health Center for their routine control because the services were sufficient in treating type 2 diabetes mellitus. From this study, it can be concluded that patients tend to comply if they feel trust in the health workers, which arises if they can feel the benefits during their therapy.
\end{abstract}

Keywords: Diabetes Mellitus Type-2; compliance; interpersonal factors; interactions; motivation

*corresponding author

Email:rani@farmasi.ui.ac.id

\section{INTRODUCTION}

Compliance to treatment for chronic diseases is a matter of great concern, including in the case of type 2 diabetes mellitus. The compliant behavior in these patients is intended to prevent complications that can lead to worsening of the condition and decrease the patient's quality of life (Das, 2020). Diabetes, as a chronic metabolic disease that occurs due to disruption of insulin work, can have a serious impact on the cardiovascular system, kidneys, eyes and nerves if not treated promptly. (Cole \& Florez, 2020; Faselis et al., 2020). In the last three decades, the prevalence of type 2 diabetes mellitus increased dramatically in 2000-2016 in developing countries, including Indonesia. It is known that in 2014, $8.5 \%$ of the world's adult population aged 18 years and over suffered from type-2 diabetes mellitus (Pusat Data dan Informasi Kementerian Kesehatan Republik Indonesia, 2018; Roglic \& World Health Organization, 2016). Moreover, in 2016, diabetes is known to be the cause of 1.6 million deaths and it is predicted that by 2022, high blood glucose levels could be the cause of 2.2 million deaths. (Centers of Diseased and Prevention, 2020; World Health Organization, 2019).
The expected therapy outcome for diabetes mellitus patient is the controlled of blood sugar levels (Novianti \& Ayu, 2019; Winahyu et al., 2020). Treatment compliance is the key to how these therapeutic targets can be achieved and need to be maintained in a person with type 2 diabetes mellitus. (Doumas et al., 2020). Many factors can affect a patient's compliant behavior in taking the medication regularly. One of the most dominant factors in influencing compliance is interpersonal factors. (Bruce et al., 2015; Krass et al., 2015). In overcoming their illness, patients tend to seek health information from various sources, either from health professionals, family, or even friends (Adikusuma, 2018). Interpersonal factors, especially in terms of the relationship between patients and healthcare workers, can greatly affect patient compliance in treatment, either to come for routine checks at health facilities or to take antidiabetic drugs to carry out type 2 diabetes mellitus therapy (Vignon Zomahoun et al., 2015). This will certainly support how patients can carry out the therapy rationally and achieve therapeutic targets to stabilize blood sugar.

Many healthcare professionals have made efforts to improve patient compliance, but they still have not 
achieved optimal results (Kirkman et al., 2015). Various methods such as patient counselling and providing drug information as well as the importance of compliance have been used. However, there are still cases of noncompliance in the community. A preliminary study that was conducted in Central Bogor City Region discovered that only $9 \%$ of patients were classified as compliant. This suggests that there are problems related to compliance, even though patients often see their health care professionals for monthly routine health checks. Therefore, this study identifies various problems within the scope of interpersonal factors between patients and healthcare workers that can affect treatment compliance behavior in patients with type 2 diabetes mellitus. This study discusses how patients view the health services provided by health workers where they do medical checkups regularly, what patients experience in taking antidiabetic drugs, and how health workers efforts to ensure patients' compliance. By understanding the problems in the interpersonal relationship between patients and health workers, it is possible to identify patterns of problems that occur between health workers and patients. Thus, it is easier to find solutions to noncompliance in a focused and directed manner.

\section{METHODS}

This is a qualitative study design uses a phenomenological method, where researchers took the opportunity to explore in-depth perceptions, and lived experiences of the research participants, to identify the interpersonal relationship issue between patients and healthcare workers (Guénette et al., 2015; Tiktin et al., 2016). The research was conducted in Central Bogor District, specifically in the work areas of the Sempur, Belong, and Merdeka Community Health Center during MarchAugust 2020. The city of Bogor has diverse population characteristics, as it is a densely populated area with an even distribution of age, education, economic level, and occupation, so it is hoped that this research obtains a variety of perceptions. This study involved informants as a source of data. The informants of this study were patients and health workers.
The patient informant is a type 2 diabetes mellitus patient who has been confirmed by the local Community Health Center. Most of the patients in this study were women $(76 \%)$ categorized as adults $(60 \%)$ and were housewives (73\%). Most of the patients lived with their families (84\%). Twelve healthcare workers involved in this study were doctors, pharmacists, nutritionists, and nurses. Each Community Health Center sent four different types of health workers so that each type of health worker is 3 people with an average of being professional graduates $(60 \%)$ and all of them are still in working productive age (25-60 years) and have worked for more than 5 years (75\%). Data were collected using in-depth interviews with twenty patients with type-2 diabetes mellitus and focus group discussions with health workers from Community Health Center. Data collection techniques can be seen in more detail in Table 1 .

This research has obtained ethical permission from the Research Ethics Committee of the Faculty of Medicine, University of Indonesia. The informants involved in this study have agreed to be actively involved in the research by signing the informed consent. The sampling technique for patients was carried out by using snowball sampling with verification of information from local health workers, while the health workers associated with this study were health workers who were active in patient therapy activities. In this study, doctors, pharmacists, nutritionists, and nurses were selected and included as the total sampling. The data that has been collected in this study are validated by confirming it to the informants after the interview. Interviews were conducted using two methods, namely by telephone and interview data confirmation during direct observation. Probing technique is applied in the interview to confirm the information obtained. The data from the interviews were then being re-verified in an on-site focus group session along with the confirmation of the data on the patient's medication record. The data obtained from indepth interviews and focus group discussions were then transcribed and content analysis was visualized in the form of interview excerpts and descriptive statistics.

Table 1. Informants and data collection techniques in research

\begin{tabular}{|c|c|c|c|c|c|c|c|c|}
\hline \multirow[t]{2}{*}{ No } & \multirow[t]{2}{*}{ Informant } & \multirow[t]{2}{*}{$\begin{array}{l}\text { Total } \\
\text { (persons) }\end{array}$} & \multicolumn{2}{|c|}{$\begin{array}{l}\text { Merdeka } \\
\text { Community } \\
\text { Health Center }\end{array}$} & \multicolumn{2}{|c|}{$\begin{array}{l}\text { Belong } \\
\text { Community } \\
\text { Health Center }\end{array}$} & \multicolumn{2}{|c|}{$\begin{array}{l}\text { Sempur } \\
\text { Community } \\
\text { Health Center }\end{array}$} \\
\hline & & & IDI & $F G D$ & IDI & $F G D$ & $I D I$ & $F G D$ \\
\hline 1 & Type-2 Diabetes Mellitus Patients & 20 & $\sqrt{ }$ & & $\sqrt{ }$ & & $\sqrt{ }$ & \\
\hline 2 & Pharmacist & 3 & & $\sqrt{ }$ & & $\sqrt{ }$ & & $\sqrt{ } \sqrt{ }$ \\
\hline 3 & Doctor & 3 & & $\sqrt{ }$ & & $\sqrt{ }$ & & $\sqrt{ }$ \\
\hline 4 & Nutritionist & 3 & & $\sqrt{ }$ & & $\sqrt{ }$ & & $\sqrt{ }$ \\
\hline 5 & Nurse & 3 & & $\sqrt{ }$ & & $\sqrt{ }$ & & $\sqrt{ }$ \\
\hline
\end{tabular}

IDI: In-Depth Interview, FGD: Focus Group Discussion 


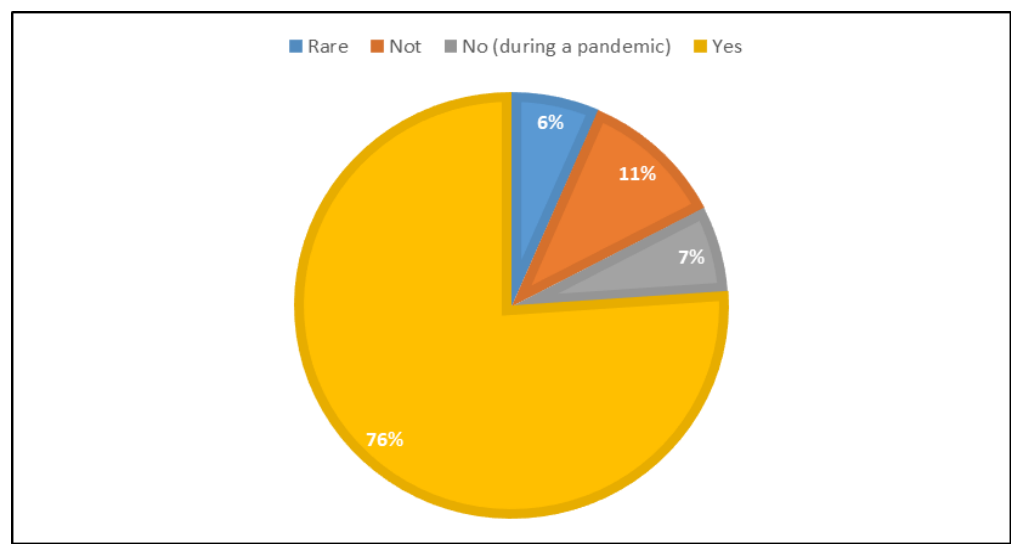

Figure 1. Frequency of routine control for type-2 Diabetes Mellitus Patients $($ Rarely $=1 ;$ No $=3$; No $($ during pandemic $)=2$; and Yes $=14)$

\section{RESULTS AND DISCUSSION}

\section{Treatment Activities}

Treatment activity is how the interaction between patients and health workers is linked (Polonsky \& Henry, 2016). Referring to the results, how patients carry out routine controls to check their health and where they usually carry out these routine controls can be identified.

From Figure 1, it can be seen that most of patients do routine control $(76 \%)$. Another and $11 \%$ patients did not do routine control, $6 \%$ patients rarely do, and and the rest did not do control at all during the Corona Virus Disease-19 pandemic. In this case, the intensity of control activities carried out were unknown. On average, patients cannot state how often they carry out routine controls to health facilities for diabetes checks, or other examinations.

\section{"... If I should come once a month for control,} then I came once a month. If once in two weeks, then I came once in two weeks..."

$$
\text { (IDI, L, Diabetes, adult) }
$$

\section{“... Before this pandemic, I went to the Community} Health Center to control my blood sugar level, as well as my blood pressure, so they are normal..."

(IDI, N, Diabetes Complications, elderly)

The Community Health Center as a place to do control for patients is greatly influenced by the ownership of BPJS or government health insurance.

\section{"...I often go to Telkom Public Health Care because of the referral..."}

(IDI, N, Diabetes Complications, adult)

From this study, the patients' choice can also be determined by the comfort of their place of treatment. A supportive atmosphere, including the readiness of health workers in providing health services will also affect the choice of places for them to seek treatment (Newman et al., 2018; Zullig et al., 2015). Patients tend to be more compliant if the atmosphere where they are treated is conducive (Ramaiya et al., 2018).

\section{“...This Community Health Center is comfortable} because of its cleanliness. The point is everything is different now. A year or months earlier, the doctor came at 9, but now 7 or 7.30. So when we came at 8 , we don't have to wait for too long..."

(IDI, N, Diabetes Complications, elderly)

“...There are many people with lung disease in the Community Health Center, and I'm afraid to catch one, so I go to vania Clinic..."

(IDI, A, Diabetes, adult)

On the other hand, it is also known that there are patients who refuse to go to a health facility, in this case, Community Health Center. Some patients may prefer other places because they are afraid of having to go to Community Health Centeras the condition makes them feel uncomfortable. Cleanliness can be an attraction for patients to be willing to go for check-up (Egbujie et al., 2018). From the perspective of the patient in general, health facilities are dirty places with big potential for the spreading of an infection (Shams et al., 2016). Bad services and health workers who are not disciplined in applying work protocols will contribute to the reluctance of patients to come to visit (Adhikary et al., 2018; Williams et al., 2017). Uncomfortable conditions will make patients feel distrustful of the services provided by these health facilities. The trust within patients in going to a health facility will affect their compliance in their treatment (Bakar et al., 2016). 


\section{Consultation and Treatment Motivation}

In doing their treatment, the patients consult with health professionals regarding their health condition (Bagonza et al., 2015). Patients usually talk about their illness or consult their medicines (Kc et al., 2019; Shaha et al., 2019). Some of the content of the consultation carried out included directions regarding drug use, and complaints, as well as how they used to adjust their diet.

"... Usually, you are told to take the medicine for the sugar level and high blood pressure. We talked about our complaints and was recommended by the doctor to take this medicine for the medication. When I was in the cohort, we are told to take this medicine and I did... "

(IDI, PAS, Diabetes Complications, adult)

“... The doctor told me something regarding my consultation then I followed him, I followed my programs ..."

(IDI, ES, Diabetes Complications, elderly)

Finding from previous research, it was found that some patients are happy with the healthcare workers whom they consult to. The doctor's attitude will certainly provide his own perspective for the patient, and in the end the patient's perception of the doctor will influence their compliance behavior (Thepwongsa et al., 2017). A friendly and open impression brings comfort to patients, so they will also provide feedback accordingly (Jalil et al., 2017). Patients will freely tell what they felt without being hesitant.

“... The doctor is also friendly, it doesn't make us stressful, because we are already sick and depend on them, but here provides is a good service ..."

(IDI, A, Diabetes, adult)

“... Very well, who has not got their medicine can go from the from back door of the Public Health Care because right now in this situation we did not pass through other patients..."

(IDI, R, Diabetes Complications, elderly)

The form of doctor's attention is also not always in the form of discussion during a consultation, but there are other methods used. These methods include giving special attention. In fact, the suggestions given by health workers in the consultation process will be the main key of the consultation itself (Iqbal et al., 2017; Thepwongsa et al., 2017). The suggestions that have an impact in influencing the patient is closely related to the style of the consultation (Linmans et al., 2015). The content provided may be similar from one health worker to another, but differences in style will have different effects (Saisho, 2018). The method can be assessed as a different perspective by the patient, as shown in the following statement.

"...If my blood sugar level is good, they tell me to maintain it. If not, they tell me what to do. They remind me to always do my exercise and wake up early to have morning walk. The doctor is a bit talkative but it feels like we can discuss anything like we're siblings ... “

(IDI, NH, Diabetes Complications, elderly)

Patients may receive a variety of suggestions or input from health professionals when they have a consultation. Consultations carried out by patients with various health professionals will give patients various perspectives on every information they receive. (Twigg et al., 2015). This encourages patients to compare the information or forms of consultation received from these various health professionals.

“...It's confusing when they told me I can use BPJS (national health insurance) to check my teeth but in fact I can't..."

(IDI, SM, Diabetes Complications, adult)

Patients who feel comfortable with certain health workers will be interested in participating in activities organized related to health. It proves that a pleasing experience will encourage the patient to follow all related matters. (Murphy et al., 2015). Patients are encouraged to participate in all forms of activities to receive benefits similar to the experiences they have received, for example in the process of consulting with health workers (Harvey, 2015; Varming et al., 2015). If the patient feels comfortable during the consultation, then every other opportunity is open as he will follow (Linmans et al., 2015). It also proves that if the patient feels comfortable with the consultation, he will be more likely to follow the directions given.

“...As what I've mentioned, as I joined prolanist (program for chronic disease patient held by Community Health Center), the health workers give attention to me, they're all kind, thank God. that's why we are often being reminded that if for example the medicine runs out or before it runs out or for example, if we want to ask for it in the lab..."

(IDI, M, Diabetes Complications, adult)

"... Yes, I like to follow it once a month, if for example there is counseling, I went there and never miss ..."

(IDI, L, Diabetes, adult) 


\section{Phenomenon of Drug Use and Compliance}

The visible benefits will encourage patients to be more compliant. The benefit can be seen as an achievement for the patient, as he feel that he got the benefit after doing the advice given (Vluggen et al., 2018). This is an important form of encouragement for the patient. Patients need to be appreciated if they have reached the expected blood sugar target (Grohmann et al., 2017). This achievement certainly needs to be known by patients, so that they can understand what efforts need to be carried out as part of a therapy strategy. This success encouraged patients to maintain it in the future (Odnoletkova et al., 2016; Seehusen et al., 2019).

"...Thank God if everything is great, the doctor said to maintain the level by taking medications also..."

(IDI, M, Diabetes Complications, adult)

“...If I take the medicine routinely it feels better..." (IDI, N, Diabetes, adult)

“...I've ever not taken any medications at all for a week, but I feel comfortable if I took it so I do it until now..."

(IDI, MW, Diabetes Complications, adult)

From several statements given by patients, there are statements that often describe drug dependence. Patients feel that taking diabetes medication is an addiction and feel that they need to carry out the advice given by a doctor so that they can then be free from the use of these antidiabetic drugs. Some of these statements indicate that there is a potential for patient non-adherence, in which case the patient may feel bored from taking medication. Some of the factors that can contribute to this are how patients also hear unpleasant information regarding the use of antidiabetic drugs, so they feel the need to get away from using these drugs.

“...What the doctor said is always true. But I like trying things like consuming herbal drinks when I ran out of money..."

(IDI, SM, Diabetes Complications, adult)

“...For six months my HbA1C continue to drops until it gets to 4,5. The doctor said I must always take my medicine except I undergo a strict diet..."

(IDI, ES, Diabetes Complications, elderly)

“...I asked my doctor regarding the continuous amounts of medicine and vitamins, he said that it won't affect my kidney badly, but I'm afraid so sometimes I change it with herbal remedies..."

(IDI, A, Diabetes, adult)
This potential uncompliant also has been confirmed by health workers from the Community Health Center. In this case, health worker usually will provide further information to follow up this kind of patients. Patients tend to look easily feared by the conditions they are experiencing now. The hope of recovery from the disease becomes a target for patients (Bhaloo et al., 2018). However, some information related to the effect of drugs on the body, for example, will be exposed to certain organs, will make patients appear reluctant to take antidiabetic drugs.

\section{"...I rarely find patients in the Community Health Center who are afraid oftaking continuous medicines affects their kidneys. But I do find them during posbindu or home visit. If I asked where they get the information, they mentioned someone said it..."}

(FGD, Nurse, Sempur)

From this statement, it can also be indicated that many patients were not open to health personnel during the consultation session. Patients are more open during home visits (Farris et al., 2019). The condition and atmosphere of the house are more likely to cause patients to be more open when a health worker visits their house. Home pharmacy care can be a method that can be used to bring pharmacists closer to patients in order to monitor therapy (Malewski et al., 2015). In this case, the atmosphere factor will play an important role in the success of the consultation to solve problems in the patient.

The same view was expressed by doctors regarding the phenomenon of non-compliance that occurred. Patients usually feel that they cannot accept that they have diabetes. This is what encourages patients to refuse to comply with treatment because they feel that they are fine. Doctors can only advise, because the final decision remains in the hands of the patient. In such conditions, a special consultation process with the patient may be required to be able to change the patient's mindset regarding the type- 2 diabetes mellitus he or she has.

\section{“...They're in denial that they suffer from diabetes and have to take medicine for the rest of their life, for example if in two weeks of consuming the medicine they feel better, they will discontinue it...” \\ (FGD, Doctor, Sempur)}

Treatment compliance is closely related to the interactions that are built between health workers and patients (Butt et al., 2016). Pharmacists as officers at the forefront of medicine can take active steps to be able to interact with patients so that good communication 
relationships can be established (Jahangard-Rafsanjani et al., 2015; Presley et al., 2019; Siaw et al., 2017). The implementation of home medication review, drug information and counselling services, and various clinical pharmacy practices can be a means to establish communication with patients to motivate patients to comply with treatment. The knowledge of a pharmacist can be used directly to be able to carry out management therapy for patients with type-2 diabetes mellitus and can have a positive impact on increasing treatment compliance (Alhabib et al., 2016; Hughes et al., 2017). However, the pharmacy workload, which mostly takes care of medical supplies, makes monitoring treatment compliance less of a priority.

All patients gave different statements related to treatment adherence. Regarding the interpersonal aspect, various statements that arise from the results of in-depth interviews with patients can be made a word cloud that can be an interpretation model in seeing various sources of motivation for treatment in patients with type 2 diabetes mellitus. The description of the source of patient motivation in taking medication can be seen in Figure 2.

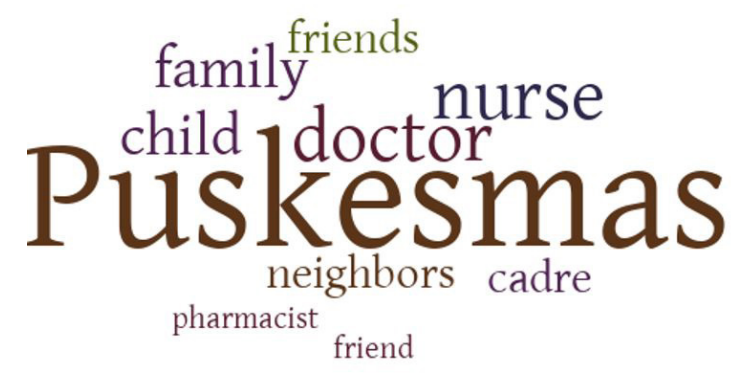

Figure 2. Word Cloud Analysis Results Based on patient statements. Puskesmas is abbreviation for Pusat Kesehatan Masyarakat (Community Health Center)

In Figure 2, the most dominant source of motivation in patients is related to health personnel and the services provided. In the word cloud, the interpretation of health workers is aimed at community health centers, doctors, nurses and pharmacists. Meanwhile, other influences come from friends, neighbors, or family. The attitude of the health worker can affect adherence because patients have regular contact with them (Malewski et al., 2015; Peimani et al., 2020). The consultation process and therapy monitoring provide a platform for interaction between patients and health workers. Patients will be able to provide their assessment of the quality of service provided. Through this consultation process, patients can be persuaded by health workers and feel cared for, so that they will follow various suggestions given to them, including in terms of treatment compliance (Zhang et al., 2020).
On the other hand, the family also has an impact on treatment compliance, this can be seen from the results of observations made on patients. In this study, it can be seen that each party will be able to have a different effect on one another. The excavation of compliance motivation through in-depth interviews and observations shows that there is synergy between the roles of health workers, friends, family, neighbors, and health cadres. The family as the smallest and closest sphere to the patient's life will be able to provide encouragement in influencing the patient's attitude, especially because of direct and frequent interactions in the patient's daily life (AlHaidar et al., 2020). Some of the patient's family members determine the patient's compliance attitude and they are directly involved in the patient's treatment process. On the other hand, it becomes a point of special consideration for health workers to approach not only the patient but also the patient's family (Daniel et al., 2020). Meanwhile, neighbors, friends, and health cadres also have an influence even though it is not too dominant and in a limited scope because of the less frequent interactions, unless they are in a community that will often interact in daily life (Jalil et al., 2017).

This study provides an overview of the importance of the influence of each person in the patient's life which can lead to the determination of adherence to these patients. With this study, the exploration of each party in the scope of interpersonal factors needs to be examined in more depth. In addition, there is a need for further research to consider factors of health service provision from the perspective of health workers. This is needed to look deeper into the obstacles experienced by health workers in providing services related to patient compliance with type 2 diabetes mellitus. Observation of the workload of each health worker who comes into contact with patients in providing services may be needed, so that it will be possible to know how to provide optimal health services in accordance with the capacity of existing health workers, especially pharmacists, to be able to contribute to the framework improve adherence to treatment of patients with type 2 diabetes mellitus in primary health facilities.

\section{CONCLUSION}

From this study, it can be concluded that patients tend to comply with treatment if they already trust and feel comfortable with the health workers who handle them. This feeling can only be achieved with optimal health services that include regular counselling, consultation and information provision during each examination. Various ways can be done as a form of innovation to build interaction with patients, including giving greetings in the context of monitoring, making home visits, and regularly communicating with patients. 


\section{ACKNOWLEDGMENTS}

The author would like to express deep gratitude to the Health Research and DevelopmentAgency of the Ministry of Health of the Republic of Indonesia for mediating between the authors and the research informants. The author also thanks to the Heads of Sempur, Belong, and Merdeka Community Health Center, as well as the health staff who were on duty and have been actively involved in the Focus Group Discussion. Not to forget, the authors would like to thank the patients who were willing to become informants. The author is also grateful to the Health Human Resources Development Agency, the Ministry of Health of the Republic of Indonesia for being willing to fund so that the research process can run smoothly.

\section{REFERENCES}

Adhikary, G., Shawon, Md. S. R., Ali, Md. W., Shamsuzzaman, Md., Ahmed, S., Shackelford, K. A., Woldeab, A., Alam, N., Lim, S. S., Levine, A., Gakidou, E., \& Uddin, Md. J. (2018). Factors influencing patients' satisfaction at different levels of health facilities in Bangladesh: Results from patient exit interviews. PLOS ONE, 13(5), e0196643. https://doi.org/10.1371/journal. pone. 0196643

Adikusuma, W. (2018). Adherence level and blood sugar control of type 2 diabetes mellitus patients who gets counseling and short messages service as reminder and motivation. Asian Journal of Pharmaceutical and Clinical Research, 11. https://doi.org/10.22159/ ajpcr.2018.v11i2.22988

Alhabib, S., Aldraimly, M., \& Alfarhan, A. (2016). An evolving role of clinical pharmacists in managing diabetes: Evidence from the literature. Saudi Pharmaceutical Journal, 24(4), 441-446. https://doi. org/10.1016/j.jsps.2014.07.008

AlHaidar, A. M., AlShehri, N. A., \& AlHussaini, M. A. (2020). Family Support and Its Association with Glycemic Control in Adolescents with Type 1 Diabetes Mellitus in Riyadh, Saudi Arabia. Journal of Diabetes Research, 2020, e5151604. https://doi.org/10.1155/2020/5151604

Bagonza, J., Rutebemberwa, E., \& Bazeyo, W. (2015). Adherence to anti diabetic medication among patients with diabetes in eastern Uganda; a cross sectional study. BMC Health Services Research, 15(1), 168. https://doi. org/10.1186/s12913-015-0820-5

Bakar, Z. A., Fahrni, M. L., \& Khan, T. M. (2016). Patient satisfaction and medication adherence assessment amongst patients at the diabetes medication therapy adherence clinic. Diabetes \& Metabolic Syndrome: Clinical Research \& Reviews, 10(2), S139-S143. https:// doi.org/10.1016/j.dsx.2016.03.015

Bhaloo, T., Juma, M., \& Criscuolo-Higgins, C. (2018). A solution-focused approach to understanding patient motivation in diabetes self-management: Gender differences and implications for primary care. Chronic Illness, 14(4), 243-255. https://doi. org/10.1177/1742395317736372

Bruce, S. P., Acheampong, F., \& Kretchy, I. (2015). Adherence to oral antidiabetic drugs among patients attending a Ghanaian teaching hospital. Pharmacy Practice, 13(1), 533. https://doi.org/10.18549/ PharmPract.2015.01.533

Butt, M., Mhd Ali, A., Bakry, M. M., \& Mustafa, N. (2016). Impact of a pharmacist led diabetes mellitus intervention on $\mathrm{HbAlc}$, medication adherence and quality of life: A randomised controlled study. Saudi Pharmaceutical Journal, 24(1), 40-48. https://oi. org/10.1016/j.jsps.2015.02.023

Centers of Diseased and Prevention. (2020). National Diabetes Statistics Report 2020. Estimates of diabetes and its burden in the United States. US Department of Health and Human Services.

Cole, J. B., \& Florez, J. C. (2020). Genetics of diabetes mellitus and diabetes complications. Nature Reviews Nephrology, 16(7), 377-390. https://doi.org/10.1038/ s41581-020-0278-5

Daniel, O., Dest, A., Munson, A., Pulley, D. V., Sadeghzadeh, C., Golin, C., \& Cené, C. W. (2020). Interventions to Enhance Patient and Family Engagement Among Adults With Multiple Chronic Conditions: A Systematic Scoping Review. Medical Care, 58(4), 407416. https://doi.org/10.1097/MLR.0000000000001274

Das, A. (2020). Fighting diabetic blindness: An urgent global issue concerning patients, physicians and public policy. Indian Journal of Ophthalmology, 68(13), 6. https://doi.org/10.4103/ijo.IJO_2342_19

Doumas, M., Imprialos, K., Stavropoulos, K., \& Athyros, V. G. (2020). Pharmacological Management of Type 2 Diabetes Complications. Current Vascular Pharmacology, 18(2), 101-103. https://doi.org/10.2174 /157016111802200101155519

Egbujie, B. A., Grimwood, A., Mothibi-Wabafor, E. C., Fatti, G., Tshabalala, A. M. E. T., Allie, S., Vilakazi, G., \& Oyebanji, O. (2018). Impact of 'Ideal Clinic' implementation on patient waiting time in primary 
healthcare clinics in KwaZulu-Natal Province, South Africa: A before-and-after evaluation. South African Medical Journal, 108(4), 311. https://doi.org/10.7196/ SAMJ.2018.v108i4.12583

Farris, K. B., Mitrzyk, B. M., Batra, P., Peters, J., Diez, H. L., Yoo, A., McKay, K., Friend, K., Danko, L., Waber, R., Marshall, V. D., \& Choe, H. M. (2019). Linking the patient-centered medical home to community pharmacy via an innovative pharmacist care model. Journal of the American Pharmacists Association, 59(1), 70-78.e3. https://doi.org/10.1016/j.japh.2018.09.009

Faselis, C., Katsimardou, A., Imprialos, K., Deligkaris, P., Kallistratos, M., \& Dimitriadis, K. (2020). Microvascular Complications of Type 2 Diabetes Mellitus. Current Vascular Pharmacology, 18(2), 117-124. https://doi.org/ $10.2174 / 1570161117666190502103733$

Grohmann, B., Espin, S., \& Gucciardi, E. (2017). Patients' experiences of diabetes education teams integrated into primary care. 9.

Guénette, L., Lauzier, S., Guillaumie, L., Giguère, G., Grégoire, J.-P., \& Moisan, J. (2015). Patients beliefs about adherence to oral antidiabetic treatment: A qualitative study. Patient Preference and Adherence, 413. https://doi.org/10.2147/PPA.S78628

Harvey, J. N. (2015). Psychosocial interventions for the diabetic patient. Diabetes, Metabolic Syndrome and Obesity: Targets and Therapy, 8, 29-43. https://doi. org/10.2147/DMSO.S44352

Hughes, J. D., Wibowo, Y., Sunderland, B., \& Hoti, K. (2017). The role of the pharmacist in the management of type 2 diabetes: Current insights and future directions. Integrated Pharmacy Research \& Practice, 6, 15-27. https://doi.org/10.2147/IPRP.S103783

Iqbal, Q., Bashir, S., Iqbal, J., Iftikhar, S., \& Godman, B. (2017). Assessment of medication adherence among type 2 diabetic patients in Quetta city, Pakistan. Postgraduate Medicine, 129(6), 637-643. https://doi.org/10.1080/003 25481.2017.1328251

Jahangard-Rafsanjani, Z., Sarayani, A., Nosrati, M., Saadat, N., Rashidian, A., Hadjibabaie, M., Ashouri, A., Radfar, M., Javadi, M., \& Gholami, K. (2015). Effect of a Community Pharmacist-Delivered Diabetes Support Program for Patients Receiving Specialty Medical Care: A Randomized Controlled Trial. The Diabetes Educator, 41(1), 127-135. https://doi. org/10.1177/0145721714559132

Jalil, A., Zakar, R., Zakar, M. Z., \& Fischer, F. (2017).
Patient satisfaction with doctor-patient interactions: A mixed methods study among diabetes mellitus patients in Pakistan. BMC Health Services Research, 17(1), 155. https://doi.org/10.1186/s12913-017-2094-6

Kc, S., S, S., Sk, S., Sm, S., \& Bk, J. (2019). Patient Characteristics Associated With Medication Adherence to Antidiabetic Drugs. Mymensingh Medical Journal : MMJ, 28(2), 423-428.

Kirkman, M. S., Rowan-Martin, M. T., Levin, R., Fonseca, V. A., Schmittdiel, J. A., Herman, W. H., \& Aubert, R. E. (2015). Determinants of Adherence to Diabetes Medications: Findings From a Large Pharmacy Claims Database. Diabetes Care, dc142098. https://doi. org/10.2337/dc14-2098

Krass, I., Schieback, P., \& Dhippayom, T. (2015). Adherence to diabetes medication: A systematic review. Diabetic Medicine, 32(6), 725-737. https://doi. org/10.1111/dme.12651

Linmans, J. J., Knottnerus, J. A., \& Spigt, M. (2015). How motivated are patients with type 2 diabetes to change their lifestyle? A survey among patients and healthcare professionals. Primary Care Diabetes, 9(6), 439-445. https://doi.org/10.1016/j.pcd.2015.02.001

Malewski, D. F., Ream, A., \& Gaither, C. A. (2015). Patient satisfaction with community pharmacy: Comparing urban and suburban chain-pharmacy populations. Research in Social and Administrative Pharmacy, 11(1), 121-128. https://doi.org/10.1016/j. sapharm.2014.05.001

Murphy, K., Chuma, T., Mathews, C., Steyn, K., \& Levitt, N. (2015). A qualitative study of the experiences of care and motivation for effective self-management among diabetic and hypertensive patients attending public sector primary health care services in South Africa. BMC Health Services Research, 15(1), 303. https://doi.org/10.1186/s12913-015-0969-y

Newman, P. M., Franke, M. F., Arrieta, J., Carrasco, H., Elliott, P., Flores, H., Friedman, A., Graham, S., Martinez, L., Palazuelos, L., Savage, K., Tymeson, H., \& Palazuelos, D. (2018). Community health workers improve disease control and medication adherence among patients with diabetes and/or hypertension in Chiapas, Mexico: An observational stepped-wedge study. BMJ Global Health, 3(1), e000566. https://doi. org/10.1136/bmjgh-2017-000566

Novianti, M., \& Ayu, M. (2019). Factors That Are Related to the Compliance of Blood Sugar Control in Mellitus Type 2 Diabetation Patients in the Cipondoh 
Puskesmas Working Area in 2019: Proceedings of the 1st International Conference on Health, 272-277. https:// doi.org/10.5220/0009593102720277

Odnoletkova, I., Buysse, H., Nobels, F., Goderis, G., Aertgeerts, B., Annemans, L., \& Ramaekers, D. (2016). Patient and provider acceptance of telecoaching in type 2 diabetes: A mixed-method study embedded in a randomised clinical trial. BMC Medical Informatics and Decision Making, 16(1), 142. https://doi.org/10.1186/ s12911-016-0383-3

Peimani, M., Nasli-Esfahani, E., \& Sadeghi, R. (2020). Patients' perceptions of patient-provider communication and diabetes care: A systematic review of quantitative and qualitative studies. Chronic Illness, 16(1), 3-22. https://doi.org/10.1177/1742395318782378

Polonsky, W., \& Henry, R. (2016). Poor medication adherence in type 2 diabetes: Recognizing the scope of the problem and its key contributors. Patient Preference and Adherence, Volume 10, 1299-1307. https://doi. org/10.2147/PPA.S106821

Presley, B., Groot, W., \& Pavlova, M. (2019). Pharmacyled interventions to improve medication adherence among adults with diabetes: A systematic review and meta-analysis. Research in Social and Administrative Pharmacy, 15(9), 1057-1067. https://doi.org/10.1016/j. sapharm.2018.09.021

Pusat Data dan Informasi Kementerian Kesehatan Republik Indonesia. (2018). Infodatin Hari Diabetes Sedunia 2018. Kementerian Kesehatan Republik Indonesia.

Ramaiya, K. L., Swai, A. M., Mutabingwa, T. K., Mwanri, A. W., \& Kagaruki, G. B. (2018). Capacity and capability of Tanzania health facilities to diagnose and manage diabetes mellitus in pregnancy. Diabetes Research and Clinical Practice, 145, 119-129. https:// doi.org/10.1016/j.diabres.2018.05.003

Roglic, G., \& World Health Organization (Eds.). (2016). Global report on diabetes. World Health Organization.

Saisho, Y. (2018). Use of Diabetes Treatment Satisfaction Questionnaire in Diabetes Care: Importance of Patient-Reported Outcomes. International Journal of Environmental Research and Public Health, 15(5), 947. https://doi.org/10.3390/ijerph15050947

Seehusen, D. A., Fisher, C. L., Rider, H. A., Seehusen, A. B., Womack, J. J., Jackson, J. T., Crawford, P. F., \& Ledford, C. J. W. (2019). Exploring patient perspectives of prediabetes and diabetes severity: A qualitative study.
Psychology \& Health, 34(11), 1314-1327. https://doi.or $\mathrm{g} / 10.1080 / 08870446.2019 .1604955$

Shaha, K. C., Khan, M. A., Akter, F., \& Jyoti, B. K. (2019). Medication Adherence Patterns to Antidiabetic Drugs among Type 2 Diabetic Patients. Medicine Today, 31(1), 19-22. https://doi.org/10.3329/medtoday. v31i1.40316

Shams, A. M., Rose, L. J., Edwards, J. R., Cali, S., Harris, A. D., Jacob, J. T., LaFae, A., Pineles, L. L., Thom, K. A., McDonald, L. C., Arduino, M. J., \& Noble-Wang, J. A. (2016). Assessment of the Overall and MultidrugResistant Organism Bioburden on Environmental Surfaces in Healthcare Facilities. Infection Control and Hospital Epidemiology, 37(12), 1426-1432. https://oi. org/10.1017/ice.2016.198

Siaw, M. Y. L., Ko, Y., Malone, D. C., Tsou, K. Y. K., Lew, Y.-J., Foo, D., Tan, E., Chan, S. C., Chia, A., Sinaram, S. S., Goh, K. C., \& Lee, J. Y.-C. (2017). Impact of pharmacist-involved collaborative care on the clinical, humanistic and cost outcomes of high-risk patients with type 2 diabetes (IMPACT): A randomized controlled trial. Journal of Clinical Pharmacy and Therapeutics, 42(4), 475-482. https://doi.org/10.1111/jcpt.12536

Thepwongsa, I., Muthukumar, R., \& Kessomboon, P. (2017). Motivational interviewing by general practitioners for Type 2 diabetes patients: A systematic review. Family Practice, 34(4), 376-383. https://doi. org/10.1093/fampra/cmx045

Tiktin, M., Celik, S., \& Berard, L. (2016). Understanding adherence to medications in type 2 diabetes care and clinical trials to overcome barriers: A narrative review. Current Medical Research and Opinion, 32(2), 277-287. https://doi.org/10.1185/03007995.2015.1119677

Twigg, M. J., Bhattacharya, D., Desborough, J. A., \& Wright, D. (2015). A drop-in clinic for patients with poorly-controlled diabetes: A community pharmacy feasibility study. International Journal of Clinical Pharmacy, 37(2), 395-402. https://doi.org/10.1007/ s11096-015-0076-5

Varming, A. R., Hansen, U. M., Andrésdóttir, G., Husted, G. R., \& Willaing, I. (2015). Empowerment, motivation, and medical adherence (EMMA): The feasibility of a program for patient-centered consultations to support medication adherence and blood glucose control in adults with type 2 diabetes. Patient Preference and Adherence, 9, 1243-1253. https://doi.org/10.2147/PPA.S85528

Vignon Zomahoun, H. T., de Bruin, M., Guillaumie, L., Moisan, J., Grégoire, J.-P., Pérez, N., Vézina-Im, L.-A., \& 
Guénette, L. (2015). Effectiveness and Content Analysis of Interventions to Enhance Oral Antidiabetic Drug Adherence in Adults with Type 2 Diabetes: Systematic Review and Meta-Analysis. Value in Health, 18(4), 530540. https://doi.org/10.1016/j.jval.2015.02.017

Vluggen, S., Hoving, C., Schaper, N. C., \& de Vries, H. (2018). Exploring beliefs on diabetes treatment adherence among Dutch type 2 diabetes patients and healthcare providers. Patient Education and Counseling, 101(1), 92-98. https://doi.org/10.1016/j.pec.2017.07.009

Williams, J. R., Halstead, V., Salani, D., \& Koermer, N. (2017). An exploration of screening protocols for intimate partner violence in healthcare facilities: A qualitative study. Journal of Clinical Nursing, 26(1516), 2192-2201. https://doi.org/10.1111/jocn.13353

Winahyu, K. M., Anggita, R., \& Widagdo, G. (2020). Factors Predicting Quality of Life among Patients with Type 2 Diabetes Mellitus in Primary Health Center in Tangerang, Indonesia. Conference, 8.
World Health Organization. (2019). Clasiffication of Diabetes Mellitus 2019.

Zhang, X., Foo, S., Majid, S., Chang, Y.-K., Dumaual, H. T. J., \& Suri, V. R. (2020). Self-Care and HealthInformation-Seeking Behaviours of Diabetic Patients in Singapore. Health Communication, 35(8), 994-1003. https://doi.org/10.1080/10410236.2019.1606134

Zullig, L. L., Gellad, W. F., Moaddeb, J., Crowley, M. J., Shrank, W., Granger, B. B., Granger, C. B., Trygstad, T., Liu, L. Z., \& Bosworth, H. B. (2015). Improving diabetes medication adherence: Successful, scalable interventions. Patient Preference and Adherence, 9, 139-149. https://doi.org/10.2147/PPA.S69651 